\title{
Effect of Cu Substituted in Ni-Zn Ferrite by Chemical Co-Precipitation Method
}

\author{
B.SURYANARAYANA*, VEMURI RAGHAVENDRA and K.CHANDRA MOULI
}

Solid State Physics \& Materials Research Labs, Dept.of Engineering Physics, Andhra University, Visakhapatnam, India

suryanarayana.badireddi@gmail.com

Received 31 October 2015 / Accepted 20 November 2015

\begin{abstract}
Ferrite particles with composition $\mathrm{Ni}_{0.2} \mathrm{Cu}_{\mathrm{x}} \mathrm{Zn}_{0.8-\mathrm{x}} \mathrm{Fe}_{2} \mathrm{O}_{4}$ where ( $\mathrm{x}=0.1,0.2,0.3,0.4,0.5$, $0.6,0.7)$ were prepared by the chemical co-precipitation method. X-ray diffraction analysis illustrated the single phase cubic spinel structure formation as $\mathrm{Cu}$ was introduced in $\mathrm{Ni}-\mathrm{Zn}-\mathrm{Fe}$ system and increase in density till $\mathrm{x}=0.5$ and then decreased and shown about $94 \%$ of the theoretical density. The particle size ranges from 18 to $90 \mathrm{~nm}$ by observation of transmission electron microscopy. The saturation magnetization $\left(\mathrm{M}_{\mathrm{s}}\right)$ in the range of 7.76 to $8.66 \mathrm{emu} / \mathrm{g}$ is observed. The magnetic properties were found to increase with the increase in $\mathrm{Cu}$ substitution up to $\mathrm{x}=0.3$. The resistivity is observed to decrease with the increment of frequency for all the samples.
\end{abstract}

Keywords: Co-precipitation, Ferrite, XRD, TEM, Magnetic

\section{Introduction}

The structural electrical, dielectrical, magnetic properties of $\mathrm{Ni}-\mathrm{Cu}-\mathrm{Zn}$ ferrites mainly depend on composition, preparation method, sintering temperature, appropriate time for sintering, density and microstructure. $\mathrm{Ni}-\mathrm{Cu}-\mathrm{Zn}$ ferrites are most flexible materials for MLCI applications due to its high permeability, low sintering temperature and high electrical resistivity ${ }^{1}$. Very fine ferrite particles can be produced by the chemical co-precipitation and sol-gel methods ${ }^{2-5}$. Wanklyn ${ }^{7}$ also used the flux method. Lerebours ${ }^{8}$ et al. prepared by annealing $\mathrm{CuO}$ and $\mathrm{Fe}_{2} \mathrm{O}_{3}$ at $1150{ }^{\circ} \mathrm{C}$ in vaccum. $\mathrm{Cu}_{0.5} \mathrm{Fe}_{2.5} \mathrm{O}_{4}$ is a Neel collinear ferromagnetic substance in which both the copper and iron are present in both of their valence states. The standard ceramic technique used to prepare Co-Zn-Copper mixed ferrite ${ }^{9}$. Zinc substituted copper ferrites have been commercially used for many years as high frequency devices such as radio frequency coils, transformer cores, rod antennas and magnetic cores of read write heads for high speed digital tapes ${ }^{10}$. The main advantage of co-precipitation method is time saving, inexpensive and control of losses in conventional ceramic method (ball-milling, mechanical grinding etc $)^{6}$. The size and shape of the ferrite particles are dependent on the synthesis process. In this paper, we used the chemical coprecipitation method to fabricate the nano-size NiCuZn ferrite powders. Effects of reaction temperature on the particle size, shape and crystallization of the precipitated particles are examined. Magnetic and micro structural properties are examined. 


\section{Experimental}

In our studies, the (i) $\mathrm{NiFe}_{2} \mathrm{O}_{4}$, (ii) $\mathrm{ZnFe}_{2} \mathrm{O}_{4}$, (iii) $\mathrm{Ni}-\mathrm{Zn}-\mathrm{Fe}_{2} \mathrm{O}_{4}$ and (iv) $\mathrm{Cu}$ substituted Ni$\mathrm{Zn}-\mathrm{Fe}_{2} \mathrm{O}_{4}$ ferrite compositions were prepared through Co-precipitation technique by using analytical reagent grade, Nickel Chloride (Merck, India), Zinc Chloride (Merck, India), Iron III Chloride (Merck, India), Copper Chloride (Merck, India) and Sodium Hydroxide ( $\mathrm{NaOH}$, Merck, India) as starting materials. Fine nanoparticles of ferrites were prepared by chemical co-precipitation method ${ }^{11}$. These chlorides were weighed in the required stoichiometric proportions and dissolved in distilled water and $\mathrm{NaOH}$ solution was added to this aqueous solution under continuous stirring at constant speed. The reaction temperature was maintained constant of $45{ }^{\circ} \mathrm{C}$ while mixing the alkaline aqueous solution. Therefore, precipitation occurred immediately and the color of suspension changed from brown to dark brown. The mixture was stirred for $2 \mathrm{~h}$ at constant temperature of $45{ }^{\circ} \mathrm{C}$. The precipitation was washed with distilled water to remove sodium and chlorine ions. The washed samples were dried in air for $20 \mathrm{~h}$. The dried powders were mixed with $5 \mathrm{wt} \%$ polyvinyl alcohol and ground well, which were compacted using uniaxial hydraulic pressing machine (with a pressure of 8-9 tonnes) and green bodies (1.7 $\mathrm{mm}$ in thickness and $6 \mathrm{~mm}$ in diameter) were sintered at $1000{ }^{\circ} \mathrm{C}$ for $1 \mathrm{hr}$ with steady rate of heating of $50{ }^{\circ} \mathrm{C}$ per hour in natural furnace chamber atmosphere to obtain sintered disks. These dried powders were analyzed for phase analysis by powder X-ray diffraction, structural analysis by Transmission electron microscopy and magnetic properties by VSM (Vibration Sample Magneto meter) techniques (VSM, JDM-13). The pellets were coated with silver paste on either side to establish good ohmic contacts with the electrodes. Resistivity as a function of temperature was measured using standard two-probe method. Effects of reaction temperature on the particle size, shape, and crystallization of the precipitated particles are examined. Magnetic and micro structural properties are examined.

\section{Results and Discussion}

$X$-ray diffraction (XRD)

X-ray diffraction peaks of \# 48-489 (standard powder file, JCPDS) of Ni-Cu-Zn-Fe spinel cubic ferrite phase (Figure 1). All the samples indicated a single phase spinel crystalline cubic ferrite. The peaks identified (220), (311), (400), (422), (511) and (440) in both series of ferries are in accordance with JCPDS file number 48-489 pattern (Figure 2). The XRD patterns ensuring phase purity. The observed reflections are strong and sharp indicating high crystallinity in samples. The patterns match well with the characteristic diffraction peaks of NiZn ferrites with no extra peaks, thus, establishing the formation of single-phase cubic spinel structure ${ }^{13,14}$. No second phases such as $\mathrm{CuO}$ or $\mathrm{CuFe}_{2} \mathrm{O}_{4}$ were detected. The lattice parameter decreases continuously with increased $\mathrm{Cu}$ substitution and can be explained on the basis of the relative ionic radii ${ }^{12}$ of $\mathrm{Cu}^{2+}$ and $\mathrm{Ni}^{2+}$ ions. Since $\mathrm{Cu}^{2+}$ ions have smaller ionic radius $\left(0.70 \mathrm{~A}^{\circ}\right)$ than those of $\mathrm{Ni}^{2+}$ ions $\left(0.78 \mathrm{~A}^{\circ}\right)$, a partial replacement of the latter by the former causes the shrinkage of the unit cell dimensions, thereby decreasing the lattice parameter. X-ray diffraction analysis illustrated the single phase cubic spinel structure formation as $\mathrm{Cu}$ was introduced in $\mathrm{Ni}-\mathrm{Zn}-\mathrm{Fe}$ system. The calculated lattice parameter ' $\mathrm{a}$ ' decreased from $8.383 \AA$ to $8.332 \AA$ as $\mathrm{x}(\mathrm{Cu})$ increased from 0.1 to 0.7 , respectively in the series of $\mathrm{Ni}_{0.2} \mathrm{Cu}_{\mathrm{x}} \mathrm{Zn}_{0.8-\mathrm{x}} \mathrm{Fe}_{2} \mathrm{O}_{4}$ ferries. In this investigation, the crystallite sizes of all the ferrites were calculated by Scherer formula [A]. The crystal size varied from 42 to $19 \mathrm{~nm}$ as $\mathrm{x}(=\mathrm{Cu})$ varied from 0.1 to 0.7 in $\mathrm{Ni}_{0.2} \mathrm{Cu}_{\mathrm{x}} \mathrm{Zn}_{0.8-\mathrm{x}} \mathrm{Fe}_{2} \mathrm{O}_{4}$ ferries series, respectively. In this investigation, the results are in accordance with the literature studies ${ }^{15,16}$. 


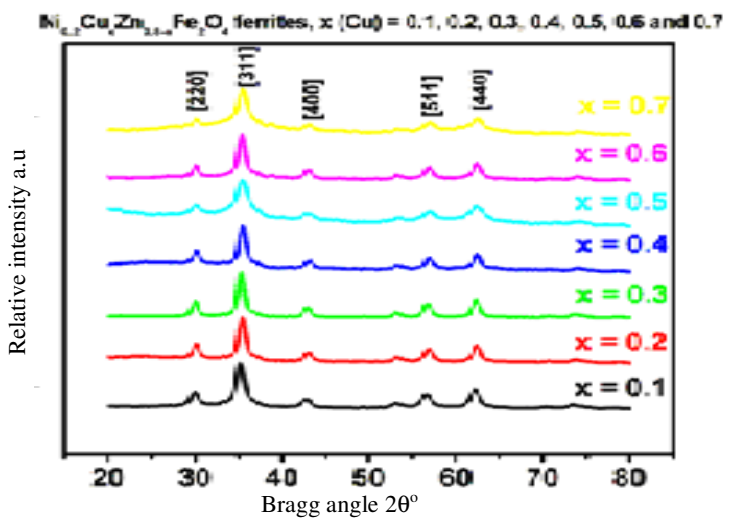

Figure 1. Powder $\mathrm{X}$-ray diffraction patterns of $\mathrm{Ni}_{0.2} \mathrm{Cu}_{\mathrm{x}} \mathrm{Zn}_{0.8-\mathrm{x}} \mathrm{Fe}_{2} \mathrm{O}_{4}$ (where $\mathrm{x}=0.1,0.2,0.3$, $0.4,0.5,0.6$ and 0.7 ) ferrites

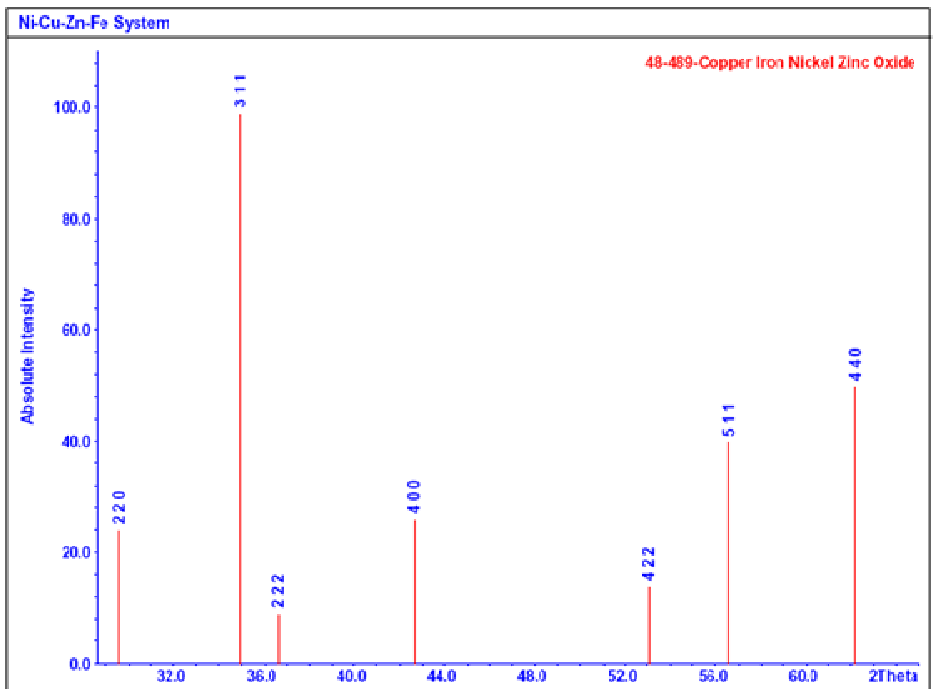

Figure 2. Powder X-ray diffraction patterns of JCPDS-48-489-Ni-Cu-Zn-Fe spinel cubic ferrite phase

\section{TEM}

The average particle size of synthesized ferrites ranged from 18 to $92 \mathrm{~nm}$ in $\mathrm{Ni}_{0.2} \mathrm{Cu}_{\mathrm{x}} \mathrm{Zn}_{0.8 \text { - }}$ ${ }_{x} \mathrm{Fe}_{2} \mathrm{O}_{4}$ (where $\mathrm{x}=0.1,0.2,0.3,0.4,0.5,0.6$ and 0.7 ) nanoferrites. In our study, the TEM images (Figures 3-5) indicates that most of the particles appear almost spherical in shape and some elongated particles are also present in the images. Some moderately agglomerated particles as well as separated particles are also present in the ferrite powders. In this study, the TEM pictures reveal that co-precipitation technique is one of the best chemical routes to obtain fine agglomerate free ferrite nano particles.

\section{Magnetic properties of nano ferrites}

The typical rectangular hysteresis loops of the synthesized nanoferrite powders and the influence of dopant concentration $(\mathrm{Cu})$ on saturation magnetization can be observed form the Figure 6. The magnetic hysteresis loops of nanoferrites were investigated at room temperature 
signifies the existence of an ordered magnetic structure in the spinel Cubic ferrite system. The increase in magnetization could be due to the fact that the individual ferrite grains act as centres on account of polarization which may be caused by the cationic vacancies. It is well known that the saturation magnetization of a spinel ferrite largely depends on its composition and particle size, while the coercive field depends on composition, particle size and shape ${ }^{17-19}$. In this study, the saturation magnetizations of nanoferrite powders have lower values compared to the values characteristic of bulk-synthesized samples. It is well established that the size of magnetic particles has an influence on the resulting saturation magnetization of the material ${ }^{17,18}$. This phenomenon was observed in several ferrite systems $^{19}$ and was explained by a magnetically "dead layer" on the surface of particles ${ }^{20,21}$, which is a consequence of non-collinear surface spins. The $\mathrm{M}_{\mathrm{s}}$ of $\mathrm{Cu}$-substituted NiZn ferrites is found to increase with the content of $\mathrm{Cu}$ and reached its maximum when substitute content up to $\mathrm{x}=0.3\left(\mathrm{Ni}_{0.2} \mathrm{Cu}_{0.3} \mathrm{Zn}_{0.5} \mathrm{Fe}_{2} \mathrm{O}_{4}\right)$ and then decrease for higher contents. This could be attributed due to the fact that the magneto crystalline anisotropy constant of $\mathrm{Fe}$ and $\mathrm{Cu}$ content. The decrease in magnetization in doped samples also suggests that $\mathrm{Cu}$ is actually replacing $\mathrm{Zn}$ in the lattice which has similar magnetic moment like $\mathrm{Zn}^{2+}$.

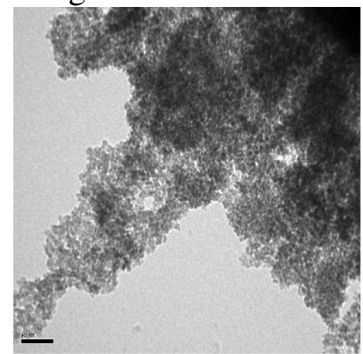

Figure 3. $\mathrm{Ni}_{0.2} \mathrm{Cu}_{0.6} \mathrm{Zn}_{0.2}$ $\mathrm{Fe}_{2} \mathrm{O}_{4}$

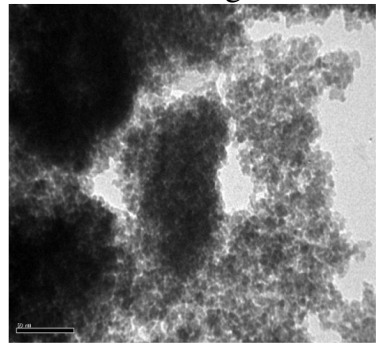

Figure 4. $\mathrm{Ni}_{0.2} \mathrm{Cu}_{0.1} \mathrm{Zn}_{0.7}$ $\mathrm{Fe}_{2} \mathrm{O}_{4}$

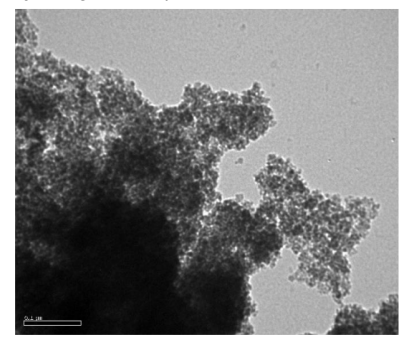

Figure 5. $\mathrm{Ni}_{0.5} \mathrm{Zn}_{0.5} \mathrm{Fe}_{2} \mathrm{O}_{4}$

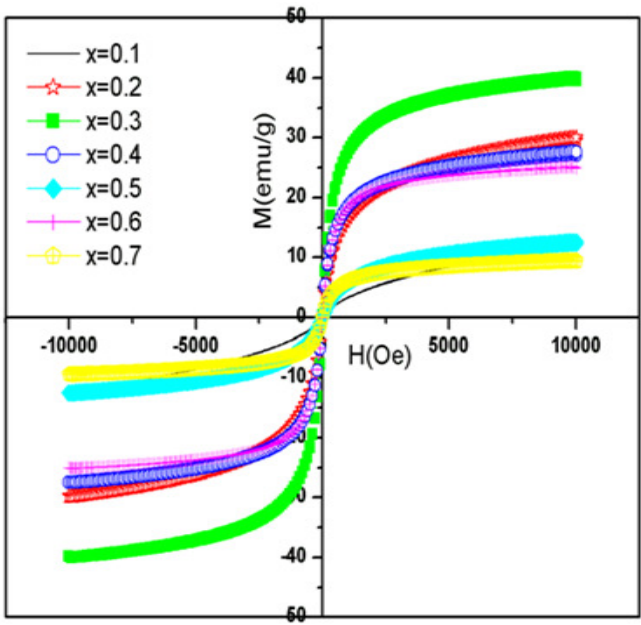

Figure 6. Magnetic properties of $\mathrm{Ni}_{0.2} \mathrm{Cu}_{\mathrm{x}} \mathrm{Zn}_{0.8 \mathrm{-}-\mathrm{F}} \mathrm{Fe}_{2} \mathrm{O}_{4}$ nanoferrite

In this study, a saturation magnetization $\left(\mathrm{M}_{\mathrm{s}}\right)$ in the range of 7.94 to $8.76 \mathrm{emu} / \mathrm{g}$ with a range of $(+5000 \mathrm{Oe})$ to $(-5000 \mathrm{Oe})$ of coercivity were observed in both series. The variation of saturation magnetic induction $\left(\mathrm{M}_{\mathrm{s}}\right)$ with $\mathrm{Cu}$ substitute concentration is shown in Figure 6 . The $\mathrm{M}_{\mathrm{s}}$ of $\mathrm{Cu}$-substituted NiZn ferrites is found to increase with the content of $\mathrm{Cu}$ and reached 
its maximum when substitute content up to $\mathrm{x}=0.3\left(\mathrm{Ni}_{0.2} \mathrm{Cu}_{0.3} \mathrm{Zn}_{0.5} \mathrm{Fe}_{2} \mathrm{O}_{4}\right)$ and then decrease for higher contents. The coercive field of these ferrites decreases with the degree of $\mathrm{Cu}^{2+}$ substitution and which might be related to the refinement of the surface of the particles, so that they can more easily change the direction of magnetic moments ${ }^{22}$. Our results are in accordance with the studies presented in the literature ${ }^{23}$.

\section{Density of sintered nanoferrites}

The substitution of $\mathrm{Cu}=\mathrm{x}=0.1$ to 0.7 in $\mathrm{Ni}_{0.2} \mathrm{Cu}_{\mathrm{x}} \mathrm{Zn}_{0.8-\mathrm{x}} \mathrm{Fe}_{2} \mathrm{O}_{4}$ nanoferrite system resulted in increment of density till $\mathrm{x}=0.5$ and then decreased and shown about $94 \%$ of the theoretical density (Figure 7). This is a significant increase at a relatively lower sintering temperature of $1000{ }^{\circ} \mathrm{C}$. In the later instance, this increase can be attributed to (i) acceleration of cation inter-diffusion due to $\mathrm{Cu}$ ions and (ii) the increase in the reactivity of the fine and enhanced ferrite grains, leading to pore reduction and volume shrinkage as also proposed by Costa $e t$ $a l{ }^{24}$ These results are in accordance with the literature studies ${ }^{25}$.

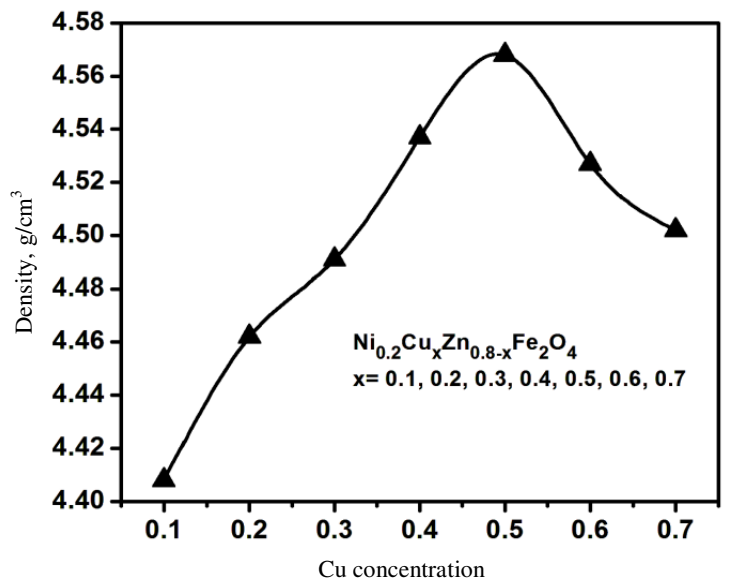

Figure 7. Density of nano ferrites

Room temperature electrical properties (Dielectric constant, dielectric loss and DC resistivity) of sintered nanoferrites

Figures $8 \& 9$ show the room temperature dielectric constant $\left(\varepsilon_{\mathrm{RT}}\right)$ and room temperature dielectric loss $\left(\right.$ Tan $\delta_{\mathrm{RT}}$ ) of sintered nanoferrites of $\mathrm{Ni}_{0.2} \mathrm{Cu}_{\mathrm{x}} \mathrm{Zn}_{0.8-\mathrm{x}} \mathrm{Fe}_{2} \mathrm{O}_{4}$ (where $\mathrm{x}=0.1,0.2$, $0.3,0.4,0.5,0.6$ and 0.7 ) nano ferrites synthesized by chemical co-precipitation method, respectively. The variation of the room temperature dielectric constant $\left(\varepsilon_{\mathrm{RT}}\right)$ with dopant $\mathrm{Cu}$ content in the nanoferrites is frequency dependent. The mechanism of polarization in polycrystalline ferrites is mainly reported to be hopping of electrons between ions of the same element but in different oxidation states. As the electrons reach the grain boundary on application of an electric field, they pile up and a charge build up takes place, causing interfacial polarization. Because the ferrites are sintered at a relatively low temperature of $1000{ }^{\circ} \mathrm{C}$, hence of polarization resulting in variable trend dielectric constant with respect to frequency and composition. Introduction of a small amounts of $\mathrm{Cu}(\mathrm{x}=0.1$ to 0.7$)$ in a predominantly NiZn ferrite results in a decrease in structural homogeneity of the ferrite which may cause a increase in polarization. The low loss values at higher frequencies show the potential of these samples for high frequency applications. It can be seen from the graphs that dielectric loss in both series is frequency dependent. 


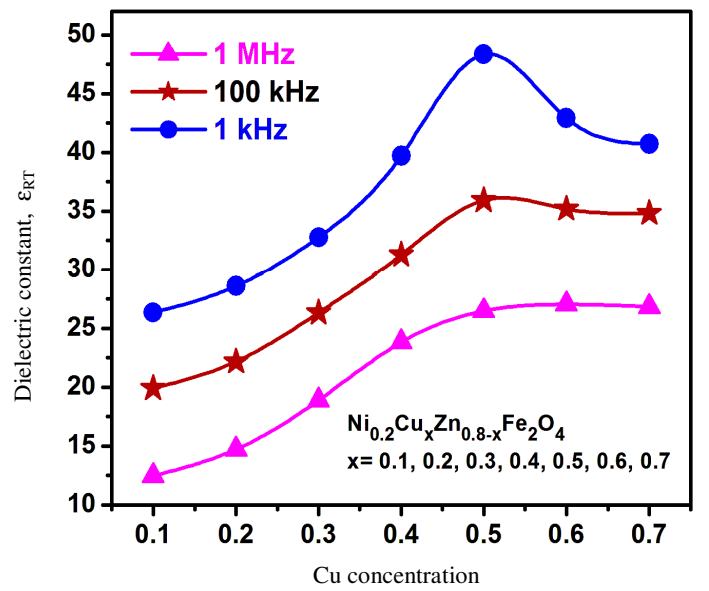

Figure 8. Room temperature dielectric constant $\left(\varepsilon_{\mathrm{RT}}\right)$

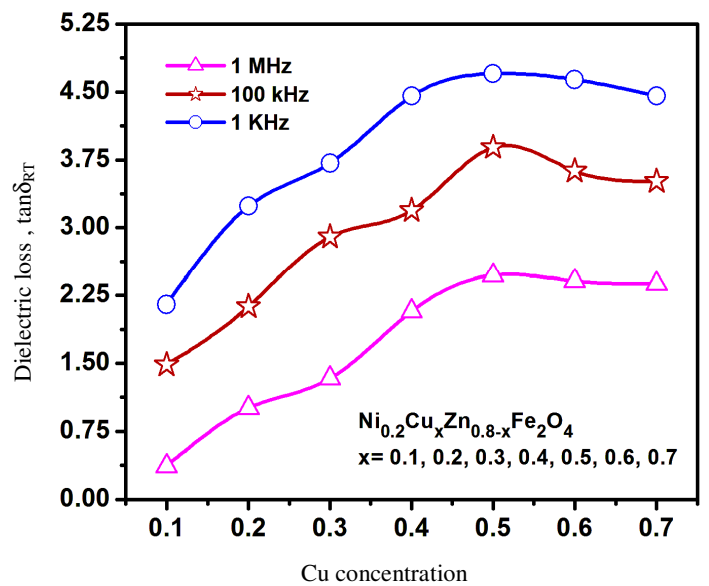

Figure 9. Room temperature dielectric loss $\left(\operatorname{Tan} \delta_{\mathrm{RT}}\right)$

\section{Room temperature DC-electrical resistivity $\left(\rho_{R T}\right)$}

It is clear from the graphs (Figure 10) that the resistivity is observed to decreased with the increment of frequency for all the samples, however the trend changed to decrease from $\mathrm{x}=0.5$ to $\mathrm{x}=0.7$. It was shown that for conduction by small polarons, dc conductivity increases with frequency ${ }^{26,27}$. It is speculated that, the decreasing trend of $\rho$ in the series from $x=0.5$ to $\mathrm{x}=0.7$ is due to the intragranular growth and thus enhanced grain $\operatorname{siz}^{28,29}$. However, the $\rho$ value continues to rise for the samples in both series and decreasing with frequency implying the mobility of electrons could be restricted at the frequency higher than $1 \mathrm{kHz}$. Our results are in agreement with the literature ${ }^{31}$. On replacement of $\mathrm{Fe}^{3+}$ ions by $\mathrm{Cr}^{3+}$ ions, which are reported to have strong preference for the octahedral (B) $\operatorname{site}^{30}$, a decrease in $\mathrm{Fe}^{3+} /$ $\mathrm{Fe}^{2+}$ ion pairs at the octahedral sites results in enhancement in the electrical resistivity of the doped $(\mathrm{Cu})$ ferrite and can be explained by electrons hopping mechanism ${ }^{32}$. Thus this investigation summarizes the increase the electrical resistivity of the nano ferrites are suitable for use in high frequency applications and as data storage devices. The dominant mechanism for electrical conduction in ferrites is the hopping mechanism. 


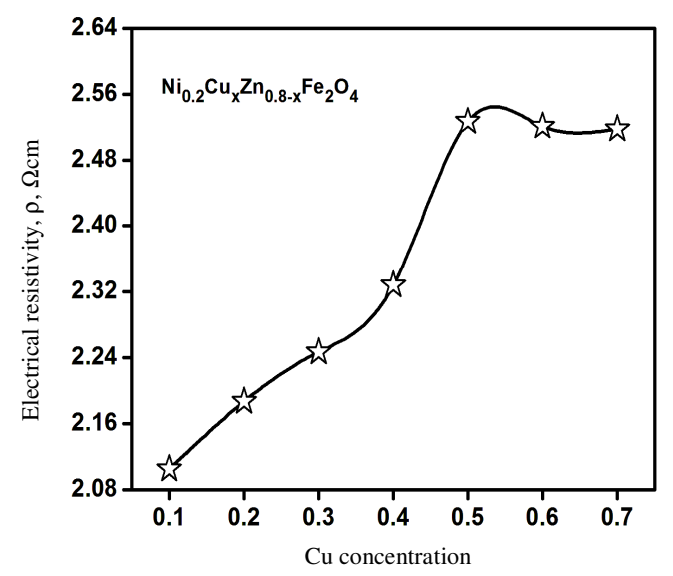

Figure 10. Room temperature electrical resistivity $\left(\rho_{\mathrm{RT}}\right)$

\section{Conclusion}

$\mathrm{Ni}_{0.2} \mathrm{Cu}_{\mathrm{x}} \mathrm{Zn}_{0.8-\mathrm{x}} \mathrm{Fe}_{2} \mathrm{O}_{4}$ (where $\mathrm{x}=0.1,0.2,0.3,0.4,0.5,0.6$ and 0.7 ) nano ferrites were synthesized by chemical co-precipitation method. All the samples indicated a single spinel crystalline phase with cubic structure formation with no indication of any other secondary or unidentified phase or incomplete reaction or impurity peaks. The particle sizes estimated through XRD and TEM measurements. The typical rectangular hysteresis loops of the nanoferrite powders and the influence of dopant concentration $(\mathrm{Cu})$ on saturation magnetisation is observed. The density is observed to be $94 \%$ of the theoretical density.

\section{References}

1. Penchal Reddy M, Madhuri W, Balakrishnaiah G, Ramamanohar Reddy N, Siva Kumar K V, Murthy V R K and Ramakrishna Reddy R, Curr Appl Phy., 2011, 11(2), 191-198; DOI:10.1016/j.cap.2010.07.005

$2 \quad$ Kuo P C and Tsai T S, J Appl Phys., 1989, 65(11), 4349-4356;

DOI:10.1063/1.343271

3 Chen C J, Bridger K, Winzer S R and Paiverneker V, J Appl Phys., 1988, 63(8), 3786-3788; DOI:10.1063/1.340640

$4 \quad$ Lin C H and Chen S Q, Chin J Mater Sci., 1983, 15, 31.

5 Yue Z, Li L, Zhou J, Zhang H and Gui Z, Mater Sci Eng., 1999, B64(1), 68-72; DOI:10.1016/S0921-5107(99)00152-X

6 Suryanarayana B, Raghavendra V and Chandra mouli K, ILCPA., 2015, 60, 20-24; DOI:10.18052/www.scipress.com/ILCPA.60.20

7 Wanklyn B M and Wondre F R, J Mat Sci Lett., 1984, 3(6), 539-543; DOI:10.1007/BF00720994

8. Lerebours B, Durr J, Hussen A D, Bonnelle J P and Lenglet M, Phys Status Solidi., 1980, A61(2), K175-K180.

9. Amer M A, Olofa O M and Henaish S A, Appl Phys Commun., 1994, 13(3-4), 255-263.

10. Kulikowski J and Leniewski A, J Magn Magn Mater., 1980, 19, 117.

11. Wei-Chih Hsu, Chen S C, Kuo P C, Lie C T and Tsai W S, Mat Sci Eng B, 2004, 111(2-3), 142-149; DOI:10.1016/j.mseb.2004.04.009

12. Shannon R D, Acta Cryst., 1976, A32, 751-767; DOI:10.1107/S0567739476001551 
13. Mukesh C Dimri, Verma A, Subhash C Kashyap, Dube D C, Thakur O P and Chandra Prakash, Mater Sci Engg., 2006, B133(1-3), 42-48;

DOI:10.1016/j.mseb.2006.04.043

14. Smit J and Wijn H P J, "Ferrites", Eindhovan, PhilipsTechnical Library, 1959, 143.

15. Ismayadi I, Hashim M, Khamirul A M and Alias R, Am J Appl Sci., 2009, 6(8), 1553 1558

16. Shen Xiang, Wang Yan-xin, Yang Xiang, Xia Yong, Zhuang Jian-feng and Tang Peiduo, Trans Nonferrous Met Soc China, 2009, 19(6), 1588-1592; DOI:10.1016/S10036326(09)60075-3

17. Kodama R H, J Magn Magn Mater., 1999, 200(1-3), 359-372; DOI:10.1016/S03048853(99)00347-9

18. Chen J P, Sorenson C M, Klabunde K J, Hadjipanayis G C, Devlin E and Kostikas A, Phys Rev., 1996, 54(13), 9288-9296; DOI:10.1103/PhysRevB.54.9288

19. Sato T, Iijima T, Seki M and Inagaki N, J Magn Magn Mater., 1987, 65(2-3), 252256; DOI:10.1016/0304-8853(87)90044-8

20. Berkowitz A E, Schule W J and Flanders P J, J Appl Phys., 1987, 39(2), 1261-1263; DOI:10.1063/1.1656256

21. Uskokovi V and Drofenik M, Materials Science Forum, 2004, 453-454, 225-230.

22. Hai-Bo Wang, Jin-Hong Liu, Wen-Feng Li, Jian-Bo Wang, Li Wang, Li-Jing Song, Shi-Jun Yuan and Fa-Shen Li, J Alloys Compounds, 2008, 461(1-2), 373-377; DOI:10.1016/j.jallcom.2007.06.095

23. Mukesh C. Dimri, A. Verma, Subhash C. Kashyap, D.C. Dube, O.P. Thakur, Chandra Prakash, Mater Sci Engg B, 2006, 133, 42-48; DOI:10.1016/j.mseb.2006.04.043

24. Costa A C F M, Tortella E, Moralli M R and Kiminani R H G A, J Magn Magn Mater., 2003, 256(1-3), 174-182; DOI:10.1016/S0304-8853(02)00449-3

25. Su H, Zhang H and Tang X, Mater Sci Eng B, 2005, 17(3), 231-234; DOI:10.1016/j.mseb.2004.11.028

26. Shrotri J J, Kulkarni S D, Deshpande C E, Mitra A, Sainkar S R, Anil Kumar P S and Date S K, Mater Chem Phys., 1999, 59(1), 1-5; DOI:10.1016/S0254-0584(99)00019-X

27. Adler D and Feinleib J, Phys Rev B, 1970, 2(8), 3112; DOI:10.1103/PhysRevB.2.3112

28. Chougule S S, Patil D R and Chougule B K, J Alloys Compd., 2008, 452(2), 205-209; DOI:10.1016/j.jallcom.2006.11.020

29. Sun G L, Li J B, Sun J J and Yang X Z, J Magn Magn Mater., 2004, 281(2-3), 173 177; DOI:10.1016/j.jmmm.2004.04.099

30. Sharma R K, Suwalka O, Lakshmi N, Venugopalan K, Banerjee A and Joy P A, Mater Lett., 2005, 59(27), 3402-3405; DOI:10.1016/j.matlet.2005.06.004

31. El-Sayed A M, Mater Chem Phys., 2003, 82(3), 583-587; DOI:10.1016/S02540584(03)00319-5

32. Hai-Bo Wang, Jin-Hong Liu, Wen-Feng Li, Jian-Bo Wang, Li Wang, Li-Jing Song, Shi-Jun Yuan and Fa-Shen Li, J Alloys Compds., 2008, 461(1-2), 373-377; DOI:10.1016/j.jallcom.2007.06.095 